
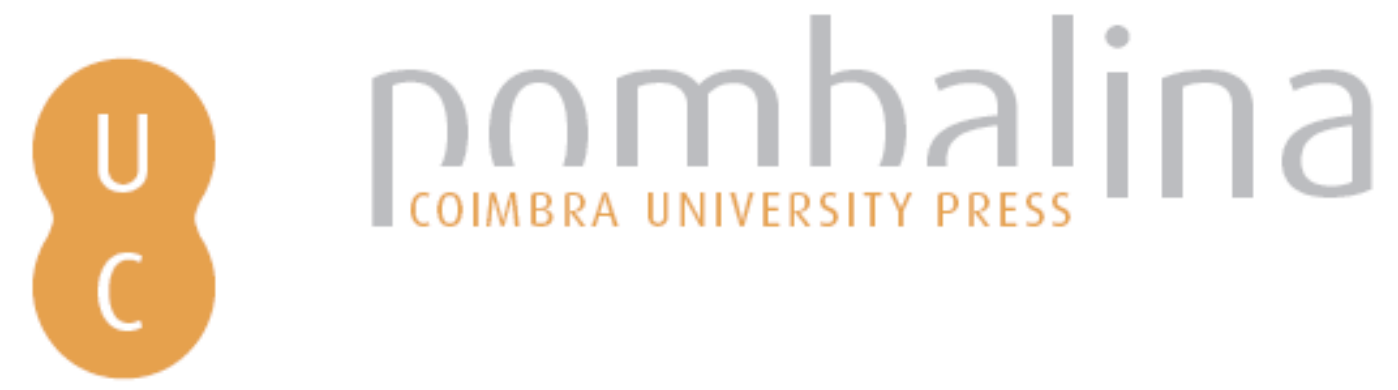

\title{
Espaço e fronteiras do mundo romano na Antiguidade Tardia: continuidade e rupturas em relação à Europa Actual
}
Autor(es):
Dias, Paula Barata
Publicado por: Associação Portuguesa de Estudos Clássicos; Imprensa da
URL persistente: Universidade de Coimbra
DOI:
URI:http://hdl.handle.net/10316.2/31804
DOI:http://dx.doi.org/10.14195/978-972-98142-2-8_2
Accessed : $\quad$ 26-Apr-2023 15:37:00

A navegação consulta e descarregamento dos títulos inseridos nas Bibliotecas Digitais UC Digitalis, UC Pombalina e UC Impactum, pressupõem a aceitação plena e sem reservas dos Termos e Condições de Uso destas Bibliotecas Digitais, disponíveis em https://digitalis.uc.pt/pt-pt/termos.

Conforme exposto nos referidos Termos e Condições de Uso, o descarregamento de títulos de acesso restrito requer uma licença válida de autorização devendo o utilizador aceder ao(s) documento(s) a partir de um endereço de IP da instituição detentora da supramencionada licença.

Ao utilizador é apenas permitido o descarregamento para uso pessoal, pelo que o emprego do(s) título(s) descarregado(s) para outro fim, designadamente comercial, carece de autorização do respetivo autor ou editor da obra.

Na medida em que todas as obras da UC Digitalis se encontram protegidas pelo Código do Direito de Autor e Direitos Conexos e demais legislação aplicável, toda a cópia, parcial ou total, deste documento, nos casos em que é legalmente admitida, deverá conter ou fazer-se acompanhar por este aviso.

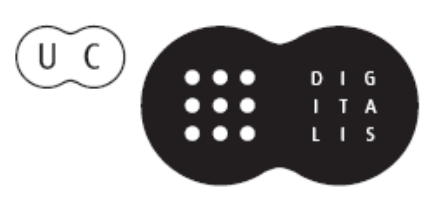




\section{Espaços e Paisagens}

\section{Antiguidade Clássica e Heranças Contemporâneas}

Vol. Il Línguas e Literaturas. Idade Média. Renascimento. Recepção

Francisco de Oliveira, Cláudia Teixeira, Paula Barata Dias (Coords.)

IMPRENSA DA UNIVERSIDADE DE COIMBRA 


\title{
ESPACO E FRONTEIRAS DO MUNDO ROMANO NA ANTTIGUIDADE TARDIA. CONTINUIDADE E RUPTURAS EM RELAÇÃO À EUROPA ACTUAL ${ }^{1}$
}

\author{
Paula Barata Dias \\ Universidade de Coimbra
}

\begin{abstract}
Late antiquity was, for the Roman World, the period of larger formal expansion, in geographical, political and cultural terms, but also the moment of great challenges: internal disaggregation, and the menace the barbarians entering in the Roman limes. This work is intended to illustrate the importance of the facts from late antiquity and Roman political measures on the contemporary configuration of Europe, who inherited the Roman efforts to preserve unity and a stable model of civilisation.
\end{abstract}

Keywords: Late Antiquity, barbarians, Constantinople, Europe, frontiers, Rome.

Palavras-chave: Antiguidade Tardia, bárbaros, Constantinopla, Europa, fronteiras, Roma.

Em 410, S. Jerónimo recorda, numa carta dirigida a Principia, o verso que Lucano criara Quid satis est, si Roma paruum est? - "O que satisfaz, se Roma não basta?". No seu contexto original, este verso aludia ao comportamento do general Pompeu na Guerra contra Júlio César, mas Jerónimo actualizou os seus referentes, considerando que este verso sintetiza o "poder da cidade de Roma". Em novos e dramáticos tempos, quase cinco séculos passados após o final da República, S. Jerónimo resolveu reescrevê-lo: Quid saluum est, si Roma perit? - "O que pode ser salvo, se Roma perece?"2. No confronto entre estes dois versos, S. Jerónimo interpreta a história romana comparando dois momentos históricos bem distintos, unificados todavia pela mesma ideia de Roma, em que esta é apresentada como condição vital e intemporal para as existências individuais e colectivas, com uma centralidade cósmica, cujo fim, improvável no verso de Lucano, temido na leitura de Jerónimo, arrasta todo um desastre civilizacional.

S. Jerónimo partilha com as elites políticas e administrativas, militares e mesmo religiosas que serviam o Império, a vivência de uma nova realidade,

\footnotetext{
${ }^{1}$ Este trabalho foi desenvolvido no âmbito da preparação da disciplina de Matrizes Clássicas da Cultura Europeia, que leccionamos na licenciatura de Estudos Europeus na Faculdade de Letras de Coimbra.

${ }^{2}$ S. Jerónimo Epistolae 127, 12 (San Jerónimo, Epistolario,J. Bautista Valero ed. e trad. 2 vols. Madrid, BAC, 1995). Diz ele, ainda capitur urbs quae totum cepit orbem "É conquistada a cidade que conquistou o mundo inteiro"; Lucano, Bellum Ciuile, 5. 274.
} 
preocupante quando comparada com os tempos áureos de Lucano. A ameaça externa às fronteiras de Roma, aos seus interesses e áreas de influência - que atingiram, no séc. III e IV, a sua dimensão máxima - conduziram os esforços romanos a uma estratégia de defesa e de sobrevivência diante de um inimigo concertado no seu poder destrutivo. Amiano Marcelino deu disso conta numa das suas Histórias:

Hoc tempore uelut per uniuersum orbem romanum, bellum canentibus bucinis, excitae gentes saeuissimae, limites sibi proximos persultabant. Gallias Raetiasque simul Alamanni populabantur; Sarmatae Pannonias et Quadi; Picti Saxonesque et Scotti, et Attacotti Brittanos aerumnis uexauere continuis; Austoriani Mauricae aliae gentes, Africam solito acrius incursabant; Thracias et diripiebant praedatorii globi Gothorum. Persarum rex manus Armeniis iniectabat (... $)^{3}$.

A partir do séc. III foi visível a estratégia defensiva que anima o esforço bélico romano, como pode constatar-se na aclamação com que os exércitos recebem a nomeação imperial de Probo Augusto:

"Probe Auguste dii te seruent (...) exemplum militiae, exemplum imperii. Dii te seruent. Adsertor rei. Felix imperes, magister militiae felix imperes (...) tuere nos rem publicam; bene tibi commitimus, quos ante seruasti. Tu Franciscus, tu Gotbicus, tu Sarmaticus, tu Parthicus, tu omnia (...) si recte cogitemus, non nobis Aurelianus, non Alexander, non Antonini, non Traianus aut Claudius requirendi sunt (...) enim uero quae mundi pars est, quam ille non uincendo didicerit? Testes sunt Marmaridae, in Africa solo uicti, testes Franci, in inuiis strati paludibus, testes Germani et Alamanni, longe a Rheni summoti litoribus. Iam uero quid Sarmatas loquor, quid Gothos, quid Parthos ac Persas atque omnem Ponticum tractum?"4.

Nestes finais do séc. III, o bom imperador é um líder militar, capaz de pacificar os remotos territórios de Roma e de afastar deles a ameaça bárbara.

${ }^{3}$ Amiano Marcelino, Historiae 26.4 5-6 (Loeb Classical Library, Harvard, 1972, t. II, p. 588). A tradução é da nossa responsabilidade: "Nesse tempo, como se por todo o mundo romano tivessem ecoado as trombetas da guerra, crudelíssimos povos se ergueram e assolavam as fronteiras que lhes eram próximas. Os Alamanos ocuparam ao mesmo tempo as Gálias e a Récia; Os Sármatas e os Quados as Panónias. Os Pictos, os Saxões e os Escotos, e também os Atacotos causaram danos continuados às tropas britânicas; Os Austorianos e outros povos mouros deslocavam-se em África com mais furor do que o habitual; hordas predadoras de Godos delapidavam as Trácias. O rei dos Persas lançava exércitos contra as Arménias...”.

${ }^{4}$ Scriptores Historiae Augustae, 28. 11.2 -12.2 (Bibliotheca Teubneriana, 1932, t. II, p. 211): "Probo Augusto, que os Deuses te protejam (...) exemplo para os exércitos, exemplo para o Império. Que os Deuses te protejam! Protector da nação! Que afortunado governes, ó Chefe dos exércitos, que afortunado governes (...) defende o Estado por nós. Confiamos de bom grado em ti, nós que já antes salvaste. Tu vencedor dos Francos, tu vencedor dos Godos, tu vencedor dos Sármatas, tu vencedor dos Partos, tu de todas as regiões vencedor! (...) em bom juízo, não precisamos de um Aureliano, nem de um Alexandre, nem de um Antonino, nem de um Trajano ou um Cláudio (...) de facto, existe alguma parte do mundo conhecida como não tendo sido por ele vencida? São testemunhas os Marmáridas, derrotados em solo africano, são testemunhas 
A segurança do Estado e a continuidade de Roma estão condicionadas pelos acontecimentos militares na periferia do Império, particularmente nas fronteiras do Oriente. Estes territórios, tão distantes do espaço ocidental, romanizado e estabilizado desde o séc. I a. C., foram lugar de condicionamento e de definição do próprio destino de Roma, e consequentemente afectaram o curso da nossa história enquanto herdeiros do legado romano. Demografia, recursos económicos, concentração urbana, particularmente nos territórios helenísticos, tornaram-nos vitais para Roma, e estratégicos na medida em que eram o único território em que esta verdadeiramente se confrontava com civilizações avançadas e potencialmente rivais, como os Persas, os Sírios e os Egípcios.

Estamos, contudo, pouco sensibilizados a considerar, dentro do legado histórico e civilizacional de que somos descendentes, a parte oriental do mundo romano. Neste domínio, a perspectiva do homem europeu típico seguiu a memória da Queda do Ocidente em 476, e de todos os acontecimentos históricos e religiosos que acentuaram a divisão do espaço romano antigo em duas partes, a ocidental e a oriental, e que trouxeram com eles uma concepção bem mais restrita e mais limitada da nossa geografia de referência e da nossa identidade civilizacional. Estas, desde o fim do Ocidente Romano, passando pelo aparecimento das primeiras nações europeias nascidas do sangue bárbaro cristianizado e romanizado, até ao projecto carolíngio, confinaram-se à margem noroeste do Mediterrâneo, ao Latim como língua de comunicação e de cultura, e ao modelo romano do cristianismo.

Em relação ao mundo antigo, politicamente romano, culturalmente grego e latino, e religiosamente diverso, incorporaram-se perdas e ergueram-se fronteiras geográficas e simbólicas que tornaram o nosso mundo, quando comparado com o antigo império romano, mais restrito e mais fragmentado, apesar dos esforços do último século para promover as vantagens do retorno a uma união política sob a UE.

Além da fragmentação do espaço romano antigo ocorrido desde o avanço na Idade Média, o que hoje é perfeitamente verificável pela diversidade linguística e pelo número de Estados europeus que deram lugar à unidade romana, surgiram novas exclusões e novas fronteiras que não existiam no mundo romano. São facilmente reconhecidas para nós, mas não existiam no passado. A fronteira islâmica, no Médio-Oriente e na África do Norte, separanos hoje de um território anteriormente integrado no império romano, mas também, já dentro da Europa política, a do cristianismo ortodoxo e de alguns países eslavos ${ }^{5}$.

os Francos, estendidos em pântanos insalubres, são testemunhas os Germanos e os Alamanos, repelidos para longe das margens do Reno. E o que direi dos Sármatas, o que direi dos Godos, dos Partos e dos Persas e de todo o conflito no Ponto..."

${ }^{5}$ Em 2003, J. Le Goff (L'Europe est-elle née au Moyen Age. Seuil, Paris, 2003) descreveu a Europa da Idade Média como resultado de uma progressiva restrição da identidade civilizacional do horizonte romano anterior. A Europa passou a significar as nações de rito romano até ao mar do norte. 
No mundo globalizado de hoje, que em teoria devia ser menos sensível aos argumentos de pertença a um grupo restrito, estão bem patentes algumas destas fronteiras que têm a sua origem nos acontecimentos da Antiguidade Tardia e da Alta Idade Média.

Por exemplo, o projecto político da União Europeia, que nasceu após a II Guerra mundial e reúne actualmente vinte e sete Estados situados dentro das fronteiras geográficas da Europa, está, na sua realização concreta, mais de acordo com a visão da Idade Média para a Europa, isto é, uma realidade política e religiosa comum - uma espécie de clube de nações do Ocidente e do Centro europeu de tradição cristã - do que com o mundo imperial romano, tal como este se configurou, entre o séc. I e o V. Esta constatação, que resulta da simples observação, não deixa, de suscitar curiosidade a quem adopta a perspectiva de um classicista. E permite-nos colocar de sobreaviso, ou pelo menos questionar a legitimidade da nossa auto-representação, nós como cidadãos da União Europeia, como herdeiros do mundo antigo.

Assim, de que herança romana se considera herdeiro o homem europeu, quando mais de dois terços do império romano, na sua amplitude, abarcaram espaços para além das actuais fronteiras políticas, económicas e culturais do espaço europeu?

Os acontecimentos da história transformaram a realidade civilizacional do mundo greco-romano, que se manteve operativa e eficaz ao nível abstracto e mais genérico dos símbolos e dos rituais do poder, verdadeiro património cristalizado de que nos servimos - mas irrelevantes para a funcionalidade das instituições políticas actuais e mesmo para a psicologia colectiva ${ }^{6}$. Temos vários exemplos dessa distância em relação à efectiva adopção de uma mundividência similar à do mundo romano. Por exemplo, o centro político da União Europeia, dito o coração da Europa, onde pulsam as Instituições Europeias, identifica-se grosso modo com o território nullius hominum entre a França e a Alemanha, o mesmo cuja centralidade estratégica na história europeia ficou definida desde a supremacia franca no séc. IX. Este espaço foi, nos séculos posteriores e até ao séc. XX, disputado palmo a palmo, constantemente empapado pelo sangue dos soldados das nações que o disputavam ou que o atravessavam. No entanto, para o mundo greco-romano, este território confinava com a periférica margem sul do Baixo Reno, a mesma que sofreria com os assaltos bárbaros na Época Tardia e que seria concedida como local de assentamento para tribos bárbaras foederatae, de tal modo estava distante das prioridades de Roma.

Outro exemplo da nossa distância em relação à mundividência grecoromana surge da discussão, perfeitamente actual, sobre a possibilidade da integração na União Europeia de países de maioria religiosa não cristã, como

\footnotetext{
${ }^{6}$ Pensamos em realidades tão banais como o destino do nome Caesar, presente no Kzar das Rússias e no Kaiser alemão; no argentus, denarius e no solidus romanos, presentes no argent francês, no dinheiro português e no dinar de Marrocos; no vocabulário das intituições políticas nas línguas europeias, quase todo de raiz greco-latina.
} 
a Turquia, a Albânia, ou mesmo Israel, e de países com uma parte significativa do seu território noutro continente, o asiático, como a Turquia e Israel, ou em África, como os países do Magreb. Se o argumento de pertença ao mundo greco-romano e de partilha desta herança fossem operativos, se, de facto, a União Europeia fosse, de algum modo, uma recuperação da unidade romana antiga, estavam os países mencionados mais legitimados à integração europeia do que os países escandinavos, bálticos e eslavos ${ }^{7}$.

Também os Estados do Norte de África, particularmente o território que hoje é a Líbia e a Tunísia, pertenceram ao Império Romano desde as Guerras Púnicas. De romanização antiga e sólida, foram vitais fornecedores de recursos materiais e agrícolas, juntamente com o Egipto, que se tornou província romana ainda no séc. I a.C. Na África Romana floresceram as ciências e as letras gregas e latinas, particularmente em redor de Alexandria, mas também de Hipona e Tagasta, com autores brilhantes como Orígenes e Agostinho. Aí a Bíblia se tornou texto verdadeiramente universal, com a sua tradução do Hebraico para o Grego em Alexandria, com as suas primeiras traduções para Latim, na África Ocidental do séc. II. Não obstante toda esta herança cultural, a possibilidade de integração destes países num projecto político comum que validasse a herança desse passado identitário é ainda mais remota do que no caso da Turquia ou de Israel.

De facto, a cultura pós-romana identificou estes povos do Norte de África como "os berberes", ou seja, os barbaroi ou barbari, os habitantes da Barbária, ou da Berbéria, termo e realidade introduzida na língua latina no séc. VIII e IX após as incursões islâmicas a partir do Norte de África ${ }^{8}$. Portanto, a elevação desta fronteira, que não existia no mundo antigo, data, pelo menos, desta Alta Idade Média.

Também os escritores bizantinos do séc. VI chamaram de Sclavoi os invasores nómadas que assolaram a Macedónia e a Tessália, e a região de que eram procedentes de Sclabenia, ou seja, os "Eslavos" e a "Eslavénia", região geograficamente identificada com a actual Polónia. Este topónimo está presente nos nomes actuais de países da Europa Central, Eslovénia e Eslováquia, por exemplo. O Latim Medieval, particularmente os escritores francos, transliteraram os termos gregos, e o etnónimo sclaui passou a ser extensivo para um tipo particular de utilização que era dada a estas pessoas, que era a de serem sclaui, ou seja "servos". Se o Português distingue, em forma e em sentido, "escravos" e "eslavos", já o Inglês tem termos parónimos, slave e Slav que conforme são pronunciados e escritos designam uma realidade ou outra. Ainda que alguns considerem esta etimologia controversa, note-se que

\footnotetext{
${ }^{7}$ Limitamo-nos a citar exemplos de países em que, em diversos momentos e com diferentes graus de discussão, foi manifestada a possibilidade da integração na UE.

${ }^{8}$ Termo adaptado do Árabe barbar, que por sua vez o recolheu do Grego. Na língua portuguesa, de acordo com J. P. Machado, o termo está documentado a partir do séc. XIV (Barbaria) e séc. XV (berbere) para identificar "o mouro sedentário, que vive da agricultura”. O nome gentílico "Barbo" tem esta origem.
} 
a mais meridional das nações eslavas, a Sérvia, conserva na sua designação o termo latino para escravo, "seruus". Isto é "terra fornecedora de servos". Em algum momento, portanto, este etnónimo Slav, além de ter migrado para o sentido de "escravo", foi apropriado por povos de matriz latina, que assim produziram o topónimo "Sérvia". São estes dois exemplos muito concretos de como a linguagem cristalizou fronteiras e imagens do outro diferentes em relação ao património clássico comum.

A toponímia da Europa actual está também bastante marcada pela memória das turbulentas deslocações populacionais iniciadas na Antiguidade Tardia, que se prolongaram até ao final da Alta Idade Média. Regiões como a Lombardia em Itália, a Borgonha em França, a Andaluzia em Espanha, a Saxónia na Alemanha, conservam na sua designação a marca de "local de assentamento", respectivamente, de Lombardos, Burgúndios e Vândalos. Para o último caso, a Saxónia é o local de origem dos Saxões, que colonizaram maciçamente a Inglaterra no séc. $\mathrm{V}$ e que justificaram o abandono romano da Britânia do seu limes setentrional. A França é, etimologicamente, o local de assentamento dos Francos, uma das tribos germânicas a quem primeiramente foi concedido o direito de se instalar em território romano ${ }^{9}$. Anglos e Jutungos, numa $2^{\text {a }}$ fase de invasões ocorridas do séc. V ao VII, deram origem, respectivamente, à Anglia à Jutlândia, a actual Dinamarca.

Além deste superestrato, a toponímia europeia preserva, em alguns casos, o adstrato, ou seja, os nomes dados pelos romanos aos povos que consigo estabeleciam contacto. Assim, a Toscânia é a terra dos Tusci ou dos Etruscos; o País Basco é a terra dos uasconii, ou basconii; a Germânia é a terra dos Germani, embora nas línguas românicas domine o etnónimo Alamania, isto é, a terra dos Alamanos, bárbaros cujas movimentações ocorreram no séc. V.

Considerar estes factos, pode levar, numa primeira leitura, à relativização do impacto da experiência romana sobre o espaço europeu, na medida em que a geografia política reproduz um mundo nascido após o domínio romano. $\mathrm{Na}$ verdade, é justamente o contrário, na medida em que o desenho actual da Europa se construiu em redor do acontecimento axial da sua história que foi o período romano, merecendo particular destaque o período crítico da ruptura política. O termo da unidade de Roma e sua memória ficou para sempre associada à génese dos povos, regiões e de nações europeias.

Nasceu também nesta Antiguidade Tardia romana a primeira leitura do termo "Europa" como uma entidade política e administrativa própria, noção que só voltará a ser materializada no séc. XX. Nos finais do séc. III, esta correspondia a uma das seis províncias administrativas da Diocese da Trácia, na parte oriental do Império Romano, região fortemente militarizada na margem Sul do Danúbio, fronteira que foi assolada pela primeira vaga goda. Podemos confirmá-lo pela ocorrência do termo na Historia Augusta, mas também

\footnotetext{
${ }^{9}$ Charles Verlinden (1954), "Frankish Colonization: A New Approach”, Transactions of the Royal Historical Society, 4 1-17.
} 
pelo Catálogo de todas as Dignidades Civis e Militares de Roma, porventura o documento que mais objectivamente atesta esta interpretação ${ }^{10}$ :

\section{Provinciae:}

Orientis quindecim:

Palaestina. Foenice. Syria.Cilicia.Cyprus.

Arabia [et dux et comes rei militaris]: Isauria. Palaestina salutaris. Palaestina secunda. Foenice

Libani. Eufratensis. Syria salutaris. Osrhoena. Mesopotamia. Cilicia secunda.

Aegypti quinque:

Libya superior. Libya inferior. Thebais. Aegyptus. Arcadia.

Asianae decem:

Pamfylia. Hellespontus. Lydia. Pisidia. Lycaonia. Frygia Pacatiana. Frygia Salutaris. Lycia.

Caria. Insulae.

Ponticae decem:

Galatia. Bithynia. Honorias. Cappadocia prima. Cappadocia secunda. Pontus Polemoniacus.

Helenopontus. Armenia prima. Armenia secunda. Galatia salutaris.

Thraciae sex:

Europa. Thracia. Haemimontus. Rhodopa. Moesia secunda. Scythia.

Segundo a Historia Augusta, Flávio Cláudio escreveu ao imperador guerreiro Aureliano solicitando-lhe auxílio para defender a "Europa" dos Godos: "Gothi oppugnandi sunt, Gothi a Thraciis amouendi. Eorum enim plerique Haemimontum Europamque uexant, qui te pugnante fugerunt. Omnes exercitus Thracicos, omnes Illyricianos totumque limitem in tua potestate constituo". O mesmo incansável Imperador, depois de ter vencido a revolta de Persas, Arménios e Sarracenos unidos pela Imperatriz Zenóbia de Palmira, abandonou a Síria e retorna à "Europa", região onde fixara os seus exércitos. Aí, ocupado com assuntos da "Europa", descurou um novo levantamento sírio, com quem havia antes estabelecido um tratado. Enquanto permaneceu na "Europa", derrotou tribos nómadas que vagueavam pela região ${ }^{11}$.

Já um dos seus sucessores, o Imperador Probo, recebeu os europenses exercitus com os quais se dirigiu para as Gálias a fim de expulsar Francos e Alamanos ${ }^{12}$. Esperaríamos que o Imperador liderasse os “exércitos de Roma”. Qual era então

\footnotetext{
${ }^{10}$ Historia Augusta, 26, 17. 2 Aurelianus (270-275), (Teubner, t. II, p. 161). Quanto ao Catálogo das Dignidades..., ver o texto, na edição de Otto Seeck http://the latin library.com/notitia.html, Notitia Dignitatum. Berolini, Weidmann, 1876. Podemos encontrar mais informação sobre este texto em J. Salisbury (1927), "On the date of the Notitia Dignitatum", The Journal of Roman Studies, 17 102-106. Goodburn, Bartholomew eds. (1976): Aspects of the Notitia Dignitatum. Oxford, British Archeological Reports, sup. XV, 224, pp.; Bury (1920), "The Notitia Dignitatum", The Journal of Roman Studies, 10 131-154.

${ }^{11}$ Ibid., 30-31, p. 171-172: "Pacato igitur Oriente in Europam Aurelianus redit uictor atque illic Carporum copias adflixisset, cum illum Carpicum senatus absentem uocasset"; "Aureliano rebus Europensibus occupato..."; "Securior denique iterum in Europam redit atque illic omnes, qui uagabuntur, hostes nota illa sua uirtute contudit".

${ }^{12}$ Ibid., Probus 28, 13, 10, p. 213.
} 
a natureza destes "exércitos da Europa"? $\mathrm{Na}$ verdade, esta designação aplicase às tropas que estavam sedeadas na região e que se mantinham na estrita dependência do Imperador. Quando Constantino derrotou os Godos, em 332, estes foram aceites como foederati com a missão de defenderem a fronteira do Danúbio $^{13}$. Era política corrente neutralizar a ameaça constituída por algumas tribos bárbaras na proximidade do limes romano pela concessão do direito de passagem e mesmo de instalação, como povo foederatus ou hospitalarius, dentro do território romano. Estes povos tornaram-se fornecedores regulares das legiões romanas, particularmente nas regiões mais sensíveis ${ }^{14}$. Assim, segundo o relato do Historiador, nos finais do séc. III, da militarizada região do Danúbio tinham sido enviadas legiões comandadas por Probo, para defender a Gália.

Estas teriam seguramente uma constituição maioritariamente bárbara, o que pode dar um sentido ominoso à expressão europenses exercitus: tropas de constituição romano-bárbara, que pugnavam mais pelo ideal de Roma do que propriamente pela sua manifestação concreta enquanto cidade capital de um império ${ }^{15}$. Esta transferência ou apropriação da simbologia e da linguagem do poder romanas pode ser documentada no período carolíngio, associada aos atributos dos imperadores e seus exércitos que, na qualidade de descendentes dos bárbaros que sobrevieram à experiência romana, se distinguem por

${ }^{13}$ Hagith Sivan, (1987) "On Foederati, Hospitalitas, and the Settlement of the Goths in A.D. 418", The American Journal of Philology, 108. 4 759-772, p. 761: "Constantine concluded another foedus whereby the Goths were to supply auxiliary forces. Furthermore, they not only served in the Constantinian army, but also contributed to civil projects, such as the building of Constantinople."This was not a new phenomenon in itself, since soldiers were closely involved in non-military projects throughout the history of the later Roman empire." Este artigo estuda o nascimento do reino visigodo com capital em Tolosa em 418, sob a autorização romana, e mostra como esta política de acomodação dos povos bárbaros no império romano tinha sido praticada já por Constantino na pacificação das fronteiras do Danúbio desde o séc. III. Godos e Francos contam-se entre os povos que melhor beneficiaram desta forma de romanização.

${ }^{14}$ E. Luttwak, (1976), The Grand Strategy of the Roman empire from the first century A. D. to the third. Baltimore, John Hopkins U.P., 255 pp. Nesta obra, o autor descreve três diferentes estratégias romanas de preservação das suas fronteiras. No Alto Império, de Augusto a Nero, a procura de Estados clientelares no perímetro externo de Roma. No segundo, desde a dinastia dos Flávios até aos Severos, o estabelecimento de linhas defensivas bem definidas, apoiadas em numerosos efectivos militares. A terceira, desde a crise do séc. III até meados do séc. IV, pelo aparecimento de exércitos regionais, dependentes de efectivos bárbaros estabelecidos no interior do limes romano.

${ }^{15}$ A expressão europenses exercitus aqui não significará, portanto, "o exército que defende a Europa" e sim "o exército originário da província da Europa". O uso de auxiliari era corrente desde o início do Império. Teodósio I (379-395) e os seus sucessores adoptaram a política de permitirem a entrada em bloco de tribos bárbaras, que recebiam pagamentos em troca de serviço militar. Na verdade, a receptio de tribos bárbaras foi já usada por Constantino, que permitira aos francos instalarem-se como laeti "soldados agricultores" no Baixo Reno. Fundada nos mecanismos da hospitalitas, esta política teve consequências desastrosas após a invasão goda de Roma, em 410. Em 418, foi permitido a este povo assentar, com permissão romana, num reino independente na Aquitânia. Roma alienava pela primeira vez o Sul da Gália como território romano. Thomas Burns (1994): Barbarians within the Gates of Rome: A Study of the Roman Military Policy and the Barbarians, a. 375-425 A.D. Bloomington, Indiana University Press, pp. 417, p. 152. 
restaurar sob a evocação de Roma um império "na Europa" de dimensões supra-nacionais ${ }^{16}$.

De facto, o enfraquecimento do poder centrífugo da cidade de Roma é um dos fenómenos associados à Antiguidade Tardia. $\mathrm{O}$ aparecimento de novas capitais provinciais, a importância estratégica dos acontecimentos militares em partes longínquas do império e particularmente a sua divisão em duas metades foram medidas administrativas que visavam adaptar o modelo romano a novas circunstâncias. Diocleciano percebeu que a instabilidade política interna, a vastidão geográfica do Império e a ameaça dos rivais, particularmente da Pérsia, eram incompatíveis com o exercício monocrático do poder. Assim, o modelo da tetrarquia, nascido com Diocleciano nos finais do séc. III, apresentava dois Augustos, o próprio Diocleciano no Oriente e Maximiano no Ocidente, que dividiam o Império a meio e partilhavam os atributos imperiais, apoiados por dois Césares, Galério e Constâncio Cloro. Estes senhores preferem locais estrategicamente relevantes, mas periféricos em relação a Roma: Milão, no sopé sul dos Alpes, Nicomédia, a actual Izmit do Norte interior da Turquia, enquanto os Césares assentam em Trier, no Sul da actual Alemanha, e em Sirmio, na actual Bósnia. Segundo Ferdinand Lot, o abandono de Roma como sede imperial, não tendo sido definitivo no séc. III, marcou o fim de Roma e o nascimento da Romania ${ }^{17}$.

À morte de Diocleciano, sucedeu o caos entre os aspirantes ao trono, a que a restauração do modelo imperial monocrático por Constantino pôs fim, em 312, com uma vitória militar sobre o seu rival, Maxêncio. O restauro da unidade, contudo, não devolveu a centralidade a Roma, e Constantino erigiu a sua nova capital na mais extrema das províncias da Trácia, precisamente a Europa. Falamos, claro, de Constantinopla, a actual Istambul, a "cidade para onde todos os caminhos confluem" ${ }^{18}$. Não deixa de ser irónico, no actual contexto político

${ }^{16}$ Em 799, o Papa Leão III pediu auxílio ao Rei Franco, Carlos Magno, para recuperar o controlo sobre Roma, a sede papal. Como recompensa, o Pontífice sagrou-o, na noite de Natal de 800, Imperador do Sacro Império Romano, restaurando a Ocidente a linhagem imperial interrompida em 476. Um poeta anónimo referiu-se a Carlos Magno como Pater Europae para celebrar este auxílio do imperador franco na defesa do Papa. (MGH Poetae Latini Aeui Karolini, I, pp. 366.381). A mesma expressão Europenses Exercitus foi usada por Isidoro, autor da Continuatio Hispana, aplicando-a aos exércitos do avô de Carlos Magno, Carlos Martel, que em Poitiers susteve o avanço meteórico do Islão vindo da Península Ibérica. Os militares francos e o seu imperador adquiriram uma aura supra-nacional que viria a ter consequências na investidura carolíngia como imperador de Roma e na sua celebração como "Pai da Europa" (Alessandro Barbero $2000^{1}$. Charlemagne Father of a Continent. University of California Press, Berkeley, (A. Cameron trad., 2004), p. 75.

${ }^{17}$ Ferdinand Lot (1991), O Fim do Mundo Antigo e o Princípio da Idade Média. Lisboa, Ed. 70, (1 $1^{\mathrm{a}}$ ed. 1927), p. 33.

${ }^{18}$ Quando é que a Europa enquanto parte administrativa do Império Romano do Oriente transferiu o seu nome para a realidade maior que está subentendida nas expressões europenses exercitus ou pater europae, associadas ao restauração do modelo imperial Supra-Nacional por Carlos Magno? O que aconteceu nos quatro séculos que medeiam as duas concepções que possa explicar esta mudança de sentido? Propomos algumas respostas, puramente especulativas: por um lado, a Europa enquanto entidade geográfica característica surge já identificada na época 
europeu, que a província da Diocese da Trácia chamada Europa seja quem com mais legitimidade etimológica e mesmo histórica pode reclamar esse nome.

O restauro da unidade imperial por Constantino não foi, contudo, definitivo, e o modelo bicéfalo, restaurando a fronteira de Diocleciano, foi mantido pelos seus sucessores. O longo reinado da Pars Orientis por um dos mais brilhantes sucessores de Constantino, Teodósio II (408-450) contribuiu para tornar o modelo imperial de "impérios gémeos", um império greco-latino, efectivo, e não uma mera resposta a uma crise temporária ${ }^{19}$.

Não estava, contudo, na intenção dos governantes, a perda da uniformidade administrativa, da comunicação, e mesmo da solidariedade entre as duas partes, o que nos indicia que a perda do Ocidente em 476 deve ter sido vivida por Zenão, o Imperador do Oriente, como uma experiência dramática, como aliás a persistência do seu sucessor Justiniano na recuperação dos territórios ocidentais no séc. VI poderá denunciar. Dois documentos históricos datados desta época confirmam este propósito de manter a unidade imperial ao nível ideológico, mas também pragmático.

A Notitia Dignitatum, documento que já referimos, está composto de duas partes, a Notitia dignitatum omnium, tam civilium quam militarium in partibus Orientis e a Notitia dignitatum omnium, tam civilium quam militarium in partibus Occidentis ${ }^{20}$.

Este documento, uma lista exaustiva das designações das autoridades civis e militares do Império romano segundo a organização de Diocleciano, estando acompanhado da circunscrição geográfica e da hierarquia, constitui

romana. Amiano Marcelino, Historiador Romano (333-392) nascido em Antioquia (Works, 3 vols. Loeb Classical Library, Harvard, 1952-1956), confirma as informações da Historia Augusta e da Notitia Dignitatum quanto ao termo "Europa". No livro 22, 8, "Descriptio Thraciarum et Sinus Pontici regionumque ac nationum Ponto adiacentium", 22, 8, 4; 22, 8, 26; 22, 8, 42 . No livro 27, 4 "Describuntur populi et VI prouinciae Thraciarum singularumque clarae urbes". Entre as seis províncias da Trácia (as referidas na Notitia Dignitatum, supra cit.), temos (27, 4, 12) "Europa omnium ultima praeter municipia urbibus nitet duabus, Apris et Perintho, quam Heracleam posteritas dixit". Duas vezes, no entanto, o entendimento do termo é menos preciso, coincidindo na geografia com a ideia que temos de "Europa como península projectada a Ocidente da Ásia". O problema maior da circunscrição geográfica da Europa prende-se com o estabelecimento claro de uma fronteira a Oriente. O texto de Amiano Marcelino dá conta dessa dificuldade. Assim, no livro 17, 7, 4 fala-se do Atlantico Mari Europaeo fronteria ocidental incontestada. No livro 31, 2, quando se descrevem os povos bárbaros da fronteira oriental (De Hunorum et Alanorum aliarumque Schitbia Asiaticae gentium sedibus et moribus), fala-se do rio Tanaís, actual Rio Don, na Ucrânia, que separa a Ásia da Europa (13): Abundans Hister aduenarum magnitudine fluenti Sauromatas praetermeat ad usque omnem Tanaim pertinentes, qui Asiam terminat ab Europa. A novidade da Antiguidade Tardia está apenas no uso do termo "Europa" com um preciso significado político e administrativo. Já o uso carolíngio pode indiciar quer a adopção do termo geográfico para qualificar uma realidade de natureza política e ideológica, quer a adesão nostálgica ao ideal imperial de Constantino e seus sucessores que tornaram a província da Europa um lugar decisivo para a conservação de Roma.

${ }^{19}$ Fergus Millar (2005), A Greek Roman Empire, Power and Belief under Theodosius II 408450. University of California Press, Londres, p. 1-2.

${ }^{20}$ Ver n. 9. 
um documento precioso para o conhecimento real da presença romana e da sua administração. Sobreviveram quatro cópias medievais de um arquétipo que, segundo os estudiosos, teria sido copiado em Ravena em meados do séc. V. A parte relativa ao Oriente teria sido composta nos inícios do séc. V e enviada ao Imperador do Ocidente para ser completada com a descrição do território por ele administrado. Este documento teria um fim eminentemente prático e protocolar, e seria utilizado para auxiliar a comunicação e os contactos entre os agentes da administração romana, ou seja, uma versão análoga ao que hoje dispomos a partir de uma lista telefónica ou de um guia de protocolo oficial. A existência e o modo de composição deste texto, em duas fases e dois locais diferentes, com reporte do documento oriental para o lado ocidental, confirma que as duas partes do império entendiam necessário e útil o conhecimento mútuo, e mantinham, dado não haver cargos exclusivos para uma só parte, soluções uniformizadoras de administração.

Formulamos uma dúvida: teria a redacção relativa à parte ocidental sido composta apenas após a recepção do documento oriental? Dada a similitude entre os dados objectivos deste documento e o que se conhece da administração de Diocleciano a Teodósio, o documento parece reproduzir um estado da administração, e não um projecto administrativo. Neste sentido, podia ter cabido ao Ocidente preencher o texto com a sua realidade administrativa e enviar uma cópia do resultado final para Constantinopla. Não se sabe se o documento final alguma vez abandonou Ravena em viagem para o Oriente, mas, de qualquer modo, a precedência do Oriente na redacção pode constituir um argumento que denuncia o reconhecimento tácito e a supremacia real do Oriente romano sobre o Ocidente ${ }^{21}$.

O princípio da precedência de Constantinopla sobre Roma, conjugado com o propósito norteador da unidade imperial, estão também patentes no segundo documento-chave para a compreensão da História da Antiguidade Tardia. O Codex Theodosianus, a compilação que reuniu os edicta (a legislação emitida pelos magistrados), as generales constitutiones (os pronunciamentos do imperador) emitidos desde Constantino, e algumas leis de juristas clássicos anteriores seleccionadas de acordo com o seu interesse, concluído em 437, pretendeu simbolizar a unidade do império romano e cristão. Aprovado no senado, em Roma, em 438, somente dez anos depois foi oficialmente enviado ao Imperador de Ravena Valentiniano III resultou da iniciativa de Teodósio, o imperador da parte oriental. Esta compilação foi escrita em Latim, reunindo as leis posteriores a Constantino e algumas anteriores que tinham sido mantidas válidas pelo primeiro imperador cristão, a que posteriormente se agregaram as nouellae, ou seja, as leis promulgadas por Teodósio entre 437 e 450 . As leis

\footnotetext{
${ }^{21}$ Outros elementos confirmam esta leitura: o facto de a redacção relativa à parte ocidental conter mais discordâncias intratextuais e mesmo mais erros em relação à realidade arqueológica, ou quando cotejado com outras fontes, acusa numa redacção menos cuidada, ou então uma administração menos eficaz, que não era capaz de acompanhar a instabilidade nas províncias formalmente a seu cargo, mas na realidade sujeitas à turbulência do séc. V.
} 
eram subscritas pelos dois Imperadores, e dadas a conhecer, embora com um lapso de tempo, nos dois territórios. Temos, portanto, um império oficialmente romano, que utiliza o Latim como língua da administração, mesmo em áreas em que o Grego era a língua dominante da vasta massa territorial e demográfica que era a metade oriental e apesar de o seu principal promotor ocupar o trono de Constantinopla ${ }^{22}$.

Como lidou a parte oriental com a perda do seu império gémeo? Em 476, o ostrogodo Odoacro pôs fim à dinastia ocidental dos imperadores romanos, data a partir da qual se restaurou a legitimidade de um só imperador romano, ou seja, o que reside em Constantinopla. É como magister militum, ou seja como súbdito de Roma que Odoacro repôs a ordem no Ocidente, expulsando o que ele entende ser um usurpador e contribuindo para declarar nula a função do senado romano. Dispôs-se, portanto, a dar continuidade, não ao Império Romano do Ocidente, mas sim à Província de Itália, sob mandato de Constantinopla. Coube a um dos seus sucessores, Teodorico Flávio,o Ostrogodo educado em Constantinopla, dirigir ao imperador Anastácio uma significativa carta, incluída na obra de Cassiodoro, em que expõe os seus propósitos de paz em relação ao Oriente e onde reconhece o poder e a inspiração emanada por Constantinopla como legítima autoridade romana, manifestando o desejo de devolver a ordem à província da Itália, sob uma só soberania: “...nós sobretudo, que graças ao vosso divino auxílio fomos educados no vosso reino, de modo a podermos de modo idêntico exercer o poder entre os romanos. $\mathrm{O}$ nosso reino é uma imitação do vosso..."23.

${ }^{22}$ Fergus Millar, op. cit., p. 10. Citamos um exemplo desta formulação. Observe- -se a dupla autoria (Teodósio e Valentiniano), a datação segundo o costume romano, a preocupação em acautelar as falsificações e em proteger a validade das leis para todo o império, embora o local de emissão seja Constantinopla. Ou seja, temos leis aprovadas "em nome de Roma e segundo o costume romano", mas fora do espaço de Roma: IMPP. THEOD(osivs) ET VALENT(INIANVS) AA. FLORENTIO P(RAEFECTO) P(RAETORI)O ORIENTIS. (...) His adicimus nullam constitutionem in posterum uelut latam in partibus occidentis alioue in loco ab inuictissimo principe filio nostrae clementiae $\mathrm{p}(\mathrm{er}) \mathrm{p}($ etuo) Augusto Valentiniano posse proferri uel uim legis aliquam obtinere, nisi hoc idem diuina pragmatica nostris mentibus intimetur. Quod obseruari necesse est in his etiam, quae per Orientem nobis auctoribus promulgantur; falsitatis nota damnandis (...) edictis propositis in omnium populorum, in omnium prouinciarum notitiam scita maiestatis augustae nostrae faciat peruenire. DAT. XV KAL. MART. CONSTANTINOPOLI D. N. THEOD(OSIO) A. XVI CONS. ET QVI FVERIT NVNTIATVS.

${ }^{23}$ Cassiodoro, Variorum Libri XII, (PL 70, col. 714). Aurélio Cassiodoro (485-585) serviu na corte de Teodorico como questor, consul, corrector, magister officiorum, praefectus praetorio et patricius: Oportet nos, clementissime imperator, pacem quaerere, qui causas iracundiae cognoscimur non habere: quando ille moribus iam tenetur obnoxius, qui ad iusta deprehenditur imparatus. Omni quippe regno desiderabilis debet esse tranquillitas, in qua et populi proficiunt et utilitas gentium custoditur. (...) [2] Et ideo, piissime principum, potentiae uestrae conuenit et honori, ut concordiam uestram quaerere debeamus, cuius adhuc amore proficimus. Vos enim estis regnorum omnium pulcherrimum decus, uos totius orbis salutare praesidium, quos ceteri dominantes iure suspiciunt, quia in uobis singulare aliquid inesse cognoscunt, nos maxime, qui diuino auxilio in re publica uestra didicimus, quemadmodum Romanis aequabiliter imperare possimus. [3] Regnum nostrum imitatio uestra est, forma boni propositi, unici exemplar imperii: qui quantum uos sequimur, tantum gentes alias anteimus. hortamini me frequenter, ut diligam senatum, leges principum amplectar, ut cuncta Italiae membra componam. 
"Uma imitação de Roma". Ficou assim reconhecido, pelos delegados da decadente cidade do Lácio, a importância política dos acontecimentos na Europa enquanto província que albergava a nova capital e os legítimos herdeiros do Império.

Face aos elementos apresentados, pensamos ter conseguido demonstrar alguns procedimentos que justificam a permanência e a continuidade da experiência romana na Europa após o fim do mundo político romano em 476 d.C., bem como o peso efectivo dos acontecimentos da Antiguidade Tardia na configuração do mundo europeu tal como o conhecemos. De facto, Roma conseguiu, pelas medidas políticas e administrativas tomadas pelos últimos imperadores, com claro protagonismo de Constantinopla, condicionar a herança adoptada pelos sucessores bárbaros, que foram alvo de processos de aculturação e de acomodação promovidos pelo próprio império romano. Os modelos civilizacionais característicos de Roma permaneceram como referências e ideais a manter ou a restaurar pelos governantes e nações futuras, que olhavam para a experiência romana como uma construção positiva.

\section{Bibliografia}

Além da que foi referida nas notas de rodapé, foram ainda consultados:

Peter Brown (1967), “The Later Roman Empire”, The Economic History Review, 20, 2.327-343.

Walter Goffart (1981), "Rome, Constantinople, and the Barbarians", The American Historical Review, 86, 2. 275-306.

(...). Romani regni unum uelle, una semper opinio sit... 